\title{
Carbon Emission and Plastic Pollution: How Circular Economy, Blockchain, and Artificial Intelligence Support Energy Transition?
}

\author{
Krishnaswamy Sankaran \\ krish@sankaran.org | Radical Innovations Group, Finland \\ Letter from Industry
}

\begin{abstract}
What drives growth becomes cancerous when it goes beyond limits. Contrary to this common sense, today, consumerism drives our economies and feeds our appetite for ever-growing wants. As a result, we are damaging our ecosystems and risking our very existence on Earth. Though too late, various efforts are promoted by governments and driven by industries to rapidly decarbonize our energy systems and sustainably consume and recycle raw materials. We have discussed two ongoing projects in the domain of energy transition and circular economy. The first one transforms industrial carbon emissions into green fuels and the second one helps in efficient and sustainable segregation and recycling of plastic waste using multi-sensor-driven AI and blockchain tools. These examples demonstrate how circular economy and energy transitions complement each other in the battle against climate change and pollution.
\end{abstract}

Keywords. Carbon emission; Plastic pollution; Recycling, Circular economy; Green fuels; Energy storage; Energy transition; Blockchain; Artificial intelligence; AI; Multi-sensor.

Cite paper as: Sankaran, K., (2019). Carbon Emission and Plastic Pollution: How Circular Economy, Blockchain, and Artificial Intelligence Support Energy Transition? - Letter from Industry, Journal of Innovation Management, www.open-jim.org, 7(4), 7-13. 


\section{Shifting Gears: From Chaos to Cure}

How we use and abuse natural resources (energy and raw materials) define our future. Gone are those days of plenty when natural resources were (ab)used as if they are going to last forever. Neither foresight nor insight guided our actions to differentiate our needs from wants. As a result, we ended up in a situation in which we did not plan to be in. On one hand, our resources are getting scarcer and population is rapidly increasing. On the other hand, we are also wasting a lot of valuable resources and polluting all ecosystems - land, water, and atmosphere (Sankaran \& Fortuny-Guasch, 2004; Sankaran, 2019, 2020). Today, consumerism drives our society and feeds our appetite for ever-growing wants. As a result, we are risking our very existence on Earth.

In the last two decades, we have been hearing a lot of concerns from various scientific communities. It took several years for policy makers and legislators to translate data into remedial actions. Still, we are far behind the ideal scenario and the consequences of our actions are contrary to our collective commitments. For example, two years after the United Nations deal with roughly 200 countries to protect the climate, the global greenhouse gas (GHG) emissions surged to a record high. Carbon dioxide $\left(\mathrm{CO}_{2}\right)$ emissions from energy use increased $1.6 \%$ in 2017 mainly due to emerging and developed economies.

Rehabilitation measures are rolled out in all domains to rapidly decarbonize all state of affairs dealing with energy use. That being said, we will perpetually be in a fire-fighting mode if we only engage in symptomatic cures without addressing how we fuel our growth-and-wants-driven society in terms of resources (energy and raw materials). This is the nexus where energy transition and circular economy meet.

Thankfully, several sectors in our society are leading change in this nexus. We will highlight a couple of projects in Radical Innovations Group, Finland that showcase our activities in circular economy and energy transition. In the first example, we will present our ongoing work to produce commercially valuable green fuels from industrial carbon emissions. Second example introduces various smart tools that we are currently developing based on blockchain and multi-sensor-driven artificial intelligence (AI) for efficient segregation and recycling of plastic waste.

\section{Energy Transition \& Circular Economy}

Circular economy is an efficient and responsible model for running our society with the aim of eliminating waste and enhancing resource (material) utility. Through various principled actions - reusing, sharing, repairing, refurbishing, remanufacturing, repurposing, and recycling we can operate a close-loop ecosystem and extend the life-cycle of products, equipment and infrastructure. Thus improving the resource utility, reducing waste, and energy consumption. The energy transition, on the other hand, is a pathway towards transformation from fossil-fuel to zero-carbon-based energy sources. Circular economy and energy transition projects can immensely benefit from the use of smart technologies supporting development of relevant policy frameworks and market instruments. 


\subsection{Green fuels from industrial carbon emissions}

Industrial carbon emissions are a major problem; but not when utilized cleverly. Case in point are different carbon capture and utilisation (CCU) technologies that transform carbon emissions to various value-added products such as fuels, carbonates, polymers, and other chemicals ( $\mathrm{Yu}$, Curcic, Gabriel, \& Tsang, 2008; Hunt, Sin, Marriott, \& Clark, 2010; Jiang, Xiao, Kuznetsov, \& Edwards, 2010; Markewitz et al., 2012; Dowell, Fennell, Shah, \& Maitland, 2017). CCU has the potential to contribute to a new economy that makes full use of emissions from industries. When we utilize these industrial carbon emissions to produce fuels with the support of renewable energy, we can realize a green circular economy. We have studied various processes to recycle $\mathrm{CO}_{2}$ from industrial emissions to produce value-added products, namely, methanol $\left(\mathrm{CH}_{3} \mathrm{OH}\right)$ and formic acid (HCOOH) (Patil \& Sankaran, 2020b). The schematic of the green circular ecosystem currently being developed in Finland is shown in Fig. 1. Our business plan will not only help in the battle against global warming, but it will also produce commercially-valuable products in an efficient and sustainable manner.

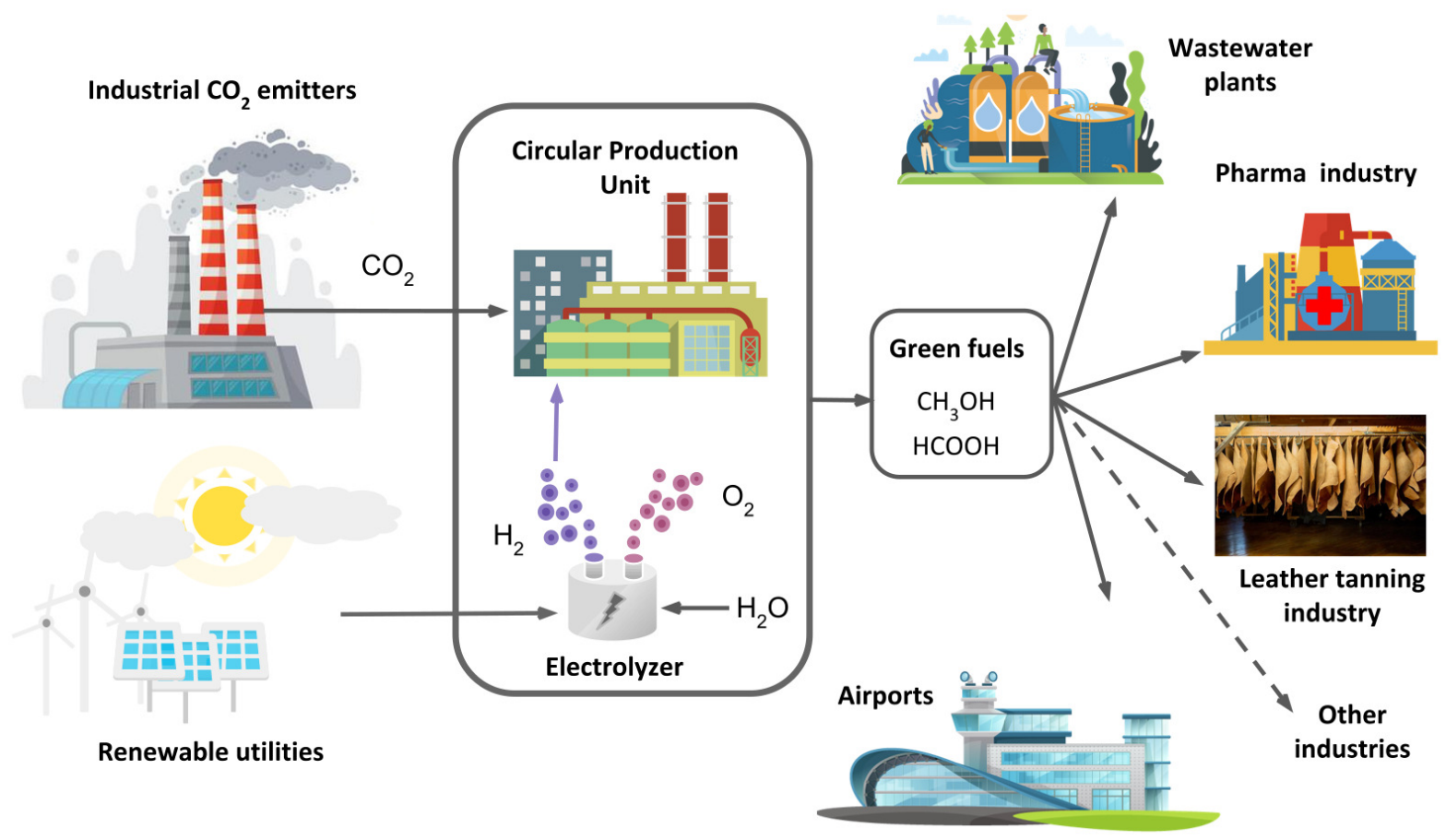

Fig. 1. Green fuel production ecosystem using industrial carbon emissions and renewable energy

Apart from these green fuels, we are also investigating pathways to produce green ammonia, which acts as an efficient medium to store renewable energy (Patil \& Sankaran, 2020a). We are presently studying the techno-economic and environmental feasibility of ammonia as a future energy source to fuel our industrial and transportation needs. 


\subsection{Plastic recycling powered by multi-sensor-driven AI and blockchain}

The word plastic resonates with two contradictory references - one relating to the revolution and the other concerning the pollution created by this man-made material in our society. The magic and the mayhem created by plastics are both incredible and disturbing. For sure, there is no simple way to get rid off this pervasive material. We need to understand and resolve the structural challenges in our system that will systematically enable proper disposal of plastic waste and encourage reusing and recycling. The biggest bottleneck is due to lack of reliable information about the availability, quantity, quality, and suitability of recycled plastic feedstock. Without such a reliable information, manufacturers are not motivated to procure recycled feedstock instead of virgin polymers (Eriksen, Damgaard, Boldrin, \& Astrup, 2018). We are developing multi-sensor-driven artificial intelligence (AI) and blockchain tools that bridge this information gap and improve plastic waste segregation and recycling processes (Patil et al., 2020). Fig. 2 illustrates how multi-sensor-driven AI tools help in retrieving vital information such as colour, size, shape, density, physical, and chemical composition of the plastic waste. Gathering such information from plastic waste greatly enhances segregation process. These collected data from plastic waste are also distributed and validated on the blockchain platform, which serves as a trust-based network (Crosby, Nachiappan, Pattanayak, Verma, \& Kalyanaraman, 2016; Drescher, 2017; Kouhizadeh \& Sarkis, 2018; Mansfield-Devine, 2017; Romano \& Schmid, 2017; Sekhri, 2018; Kouhizadeh, Sarkis, \& Zhu, 2019; Adebiyi-Abiola, Assefa, Sheikh, \& Garcia, 2019; Wang \& Qu, 2019). We use this blockchain platform as a backbone to share and validate valuable information (also called as digital transaction) between plastic waste segregators, recyclers, and feedstock buyers (manufacturers). Information transacted also contains data regarding supply, demand, specifications (quality), bidding- and offer-price of recycled feedstock as illustrated in Fig. 2. These smart tools increase the use of recycled plastics for manufacturing various products. As a result, we are able to minimize the amount of plastic waste being incinerated and dumped. Hence, circular economy of plastic protects environment and supports energy transition in three ways - reduces our dependence on fossil fuel-derived virgin plastic, minimizes carbon emission from incineration plants, and avoids pollution caused by landfills.

\section{Conclusion}

Increasing carbon emission and massive waste generation are two major challenges confronting our society. Unless we care about what and how we consume, dispose, and recycle resources, there is no way out of this man-made chaos. Several corrective measures are ongoing in different sectors to rehabilitate our ecosystems. We have discussed two ongoing projects: the first is to transform industrial carbon emissions into green fuels, and the second is to efficiently and sustainably segregate and recycle plastic waste using multi-sensor-driven AI and blockchain tools. Through these examples, we have demonstrated how circular economy supports energy transition in the battle against climate change and pollution. 


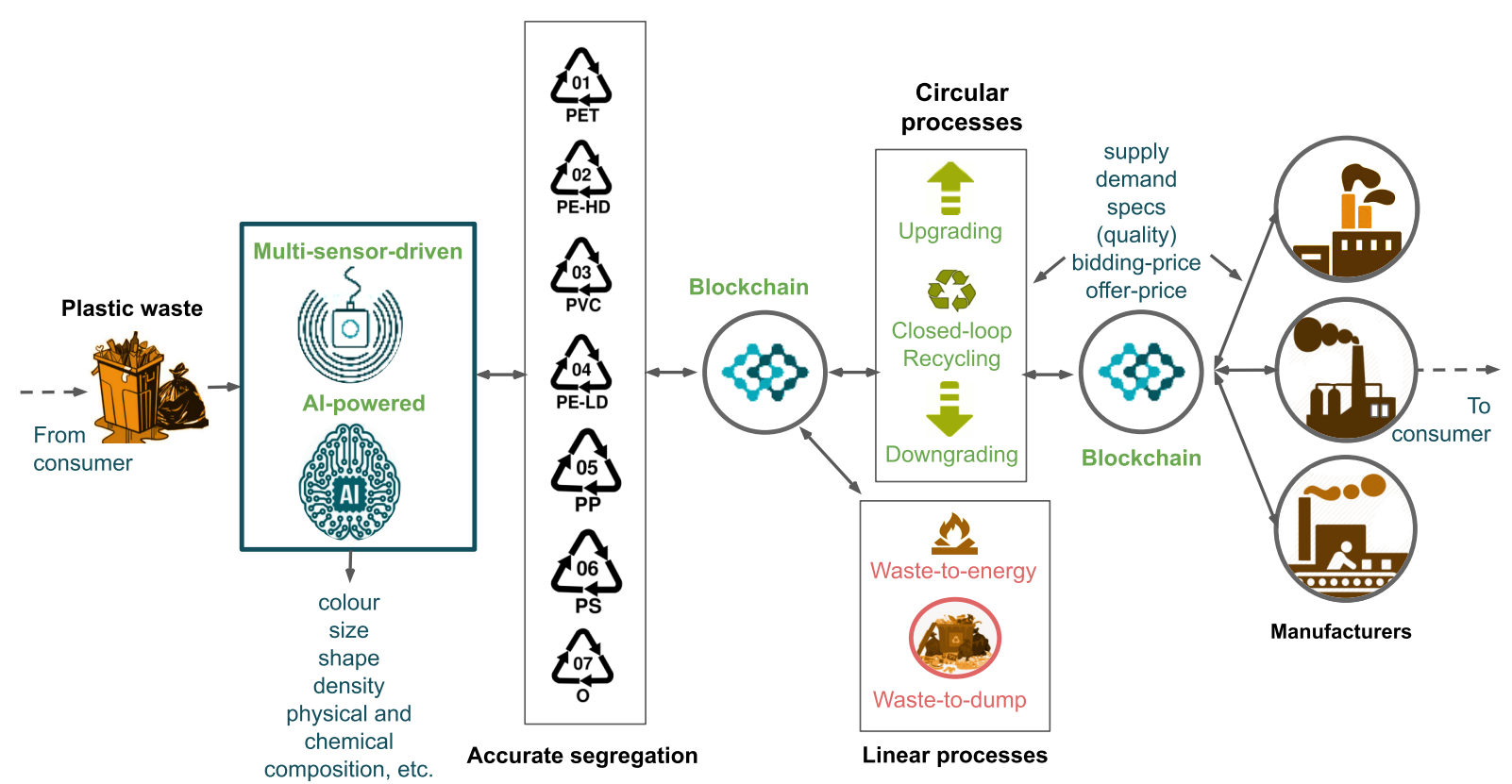

Fig. 2. Multi-sensor-driven AI and blockchain tools for efficient segregation and recycling of plastic waste.

\section{References}

Adebiyi-Abiola, B., Assefa, S., Sheikh, K., \& Garcia, J. M. (2019). Cleaning up plastic pollution in africa. Science, 365(6459), 1249-1251. doi: 10.1126/ science.aax3539

Crosby, M., Nachiappan, Pattanayak, P., Verma, S., \& Kalyanaraman, V. (2016). Blockchain technology: Beyond bitcoin. Applied Innovation Review, 2(6-10), 71.

Dowell, N. M., Fennell, P. S., Shah, N., \& Maitland, G. C. (2017). The role of $\mathrm{CO}_{2}$ capture and utilization in mitigating climate change. Nature Climate Change, 7(4), 243-249. doi: 10.1038/nclimate3231

Drescher, D. (2017). Blockchain Basics: A Non-technical Introduction in 25 Steps(1st ed.). Berkeley, California, US: Apress. doi: 10.1007/978-1-4842 -2604-9

Eriksen, M. K., Damgaard, A., Boldrin, A., \& Astrup, T. F. (2018, Nov). Quality assessment and circularity potential of recovery systems for household plastic waste. Journal of industrial ecology, 156-168. doi: 10.1111/ jiec.12822

Hunt, A. J., Sin, E. H. K., Marriott, R., \& Clark, J. H. (2010). Generation, capture, and utilization of industrial carbon dioxide. Chemistry \& Sustainability Energy\& Materials, 3(3), 306-322. doi: $10.1002 /$ cssc.200900169

Jiang, Z., Xiao, T., Kuznetsov, V. L., \& Edwards, P. P. (2010). Turning carbon dioxide into fuel. Philosophical Transactions of the Royal Society A: Mathematical, Physical and Engineering Sciences, 368(1923), 3343- 3364. doi: 10.1098/rsta.2010.0119 
Kouhizadeh, M., \& Sarkis, J. (2018). Blockchain practices, potentials, and 5 perspectives in greening supply chains. Sustainability, 10(10), 3652. doi:10.3390/su10103652

Kouhizadeh, M., Sarkis, J., \& Zhu, Q. (2019). At the Nexus of Blockchain Technology, the Circular Economy, and Product Deletion. Applied Sciences,9(8), 1712. doi: 10.3390/app9081712

Mansfield-Devine, S. (2017). Beyond Bitcoin: using blockchain technology to provide assurance in the commercial world. Computer Fraud \& Security, 2017(5), 14-18. doi: 10.1016/S13613723(17)30042-8

Markewitz, P., Kuckshinrichs, W., Leitner, W., Linssen, J., Zapp, P., Bongart, R., . . . Müller, T. E. (2012). Worldwide innovations in the development of carbon capture technologies and the utilization of $\mathrm{CO}_{2}$. Energy \& Environmental Science, 5(6), 7281-7305. doi: 10.1039/C2EE03403D

Patil, A., Bindra, P., Kulkarni, D., Qazi, M., Kshirsagar, M., \& Sankaran, K. (2020). From Trash to Cash: How Blockchain and Multi-Sensor-driven AI Can Transform Circular Economy of Plastic Waste? Administrative Sciences. (In review)

Patil, A., \& Sankaran, K. (2020a). Green Ammonia: What Feeds Our Crops Could Fuel Our Industries. Engineering Reports. (In review)

Patil, A., \& Sankaran, K. (2020b). Making Green from Black: Circular Economy of Carbon Emissions to Sustainable Fuels. Administrative Sciences. (In review)

Romano, D., \& Schmid, G. (2017). Beyond bitcoin: A critical look at Blockchain-based systems. Cryptography, 1 (2), 15. doi: 10.3390/ cryptography1020015

Sankaran, K. (2019). Protecting oceans from illicit oil spills: Environment control and remote sensing using spaceborne imaging radars. Journal of Electromagnetic Waves and Applications. 33, 2373-2403. doi: 10.1080/09205071.2019.1685409

Sankaran, K. (2020). Spaceborne radar remote sensing of ocean surfaces: Electromagnetic modelling and applications. Journal of Electromagnetic Waves and Applications, 34, 1-34. doi: 10.1080/09205071.2019.1696237

Sankaran, K., \& Fortuny-Guasch, J. (2004). Radar remote sensing for oil spill classification (optimization for enhanced classification). Proceedings of the 12th IEEE Mediterranean Electrotechnical Conference(pp. 511-514). Dubrovnik, Croatia. doi: 10.1109/MELCON.2004.1346979

Sekhri, P. (2018). Harvesting the plastic we have sowed: costs and challenges in, and a novel application of blockchain for implementing extended producer responsibility in Chile(Doctoral dissertation, Massachusetts Institute of Technology). doi: 1721.1/118522

Wang, S., \& Qu, X. (2019). Blockchain Applications in Shipping, Transporta- tion, Logistics, and Supply Chain. Smart transportation systems2019 (pp. 225-231). Springer. doi: 10.1007/978981-13-8683-1 23

Yu, K. M. K., Curcic, I., Gabriel, J., \& Tsang, S. C. E. (2008). Recent ad- vances in co2 capture and utilization. Chemistry \& Sustainability Energy 83 Materials, 1(11), 893-899. doi: $10.1002 / \operatorname{cssc} .200800169$ 


\section{Biographies}

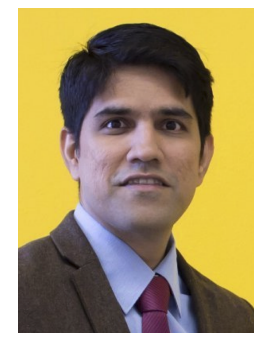

Krishnaswamy Sankaran. Dr. K. Sankaran is an established industrialist with several years of experience in energy, utilities, metals, mining, infrastructure, production, and recycling industries. He is presently the Chief Executive Officer of the Radical Innovations Group AB, Finland. He received doctorate in engineering sciences from the Swiss Federal Institute of Technology ETH Zurich, Switzerland, masters from Karlsruhe Institute of Technology KIT, Germany, and a joint executive masters in organisational development and leadership from Wharton School, Columbia University, INSEAD, and London Business School. He is a recognised thought leader and keynote speaker in many international forums. He has several years of training in Advaita philosophy. 